Research Paper

\title{
Supernatant of Bone Marrow Mesenchymal Stromal Cells Induces Periph- eral Blood Mononuclear Cells Possessing Mesenchymal Features
}

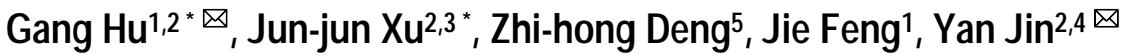

1. Department of Dermatology, Second Hospital of Xi'an Jiaotong University, Xi'an, 710004, China

2. Research and Development Center for Tissue Engineering, Fourth Military Medical University, Xi'an, 710032, China

3. College of Animal veterinary Medicine, Northwest A \& F University, Yang ling , 712100 , China

4. Department of Oral Histology and Pathology, School of Stomatology, Fourth Military Medical University, Xi'an, 710032, China

5. Department of Otolaryngology, Xijing Hospital, Fourth Military Medical University, Xi'an, Shaanxi, 710032, China

* These authors contributed equally to this study.

$\triangle$ Corresponding author: Gang Hu, Ph.D, M.D., Department of Dermatology, Second Hospital of Xi'an Jiaotong University, Xi'an, 710004, China, Tel.: 86-29-8767-9969, Fax: 86-29-8740-9503, E-mail address: gang1008@yeah.net. Yan Jin, Ph.D., Research and Development Center for Tissue Engineering, Fourth Military Medical University, Xi'an, 710032, China, Tel. 86-29-8477-6147, Fax. 86-29-8321-8039, E-mail address: yanjin@fmmu.edu.cn

(C) Ivyspring International Publisher. This is an open-access article distributed under the terms of the Creative Commons License (http:/ / creativecommons.org/ licenses/by-nc-nd/3.0/). Reproduction is permitted for personal, noncommercial use, provided that the article is in whole, unmodified, and properly cited.

Received: 2010.12.28; Accepted: 2011.03.25; Published: 2011.04.01

\begin{abstract}
Increasing evidence shows that some cells from peripheral blood fibroblast-like mononuclear cells have the capacity to differentiate into mesenchymal lineages. However, the insufficiency of these cells in the circulation challenges the cell isolation and subsequently limits the clinical application of these cells. In the present study, the peripheral blood mononuclear cells (pbMNCs) were isolated from wound animals and treated with the supernatant of bone marrow mesenchymal stromal cells (bmMSCs). Results showed these pbMNCs were fibroblast-like, had stromal morphology, were negative for CD34 and CD45, but positive for Vimentin and Collagen I, and had the multipotency to differentiate into adipocytes and osteoblasts. We named these induced peripheral blood-derived mesenchymal stromal cells (ipbMSCs). Skin grafts in combination with ipbMSCs and collagen I were applied for wound healing, and results revealed ipbMSC exhibited similar potency and effectiveness in the promotion of wound healing to the bmMSCs. Hereafter, we speculate that the mixture of growth factors and chemokines secreted by bmMSCs may play an important roles in the induction of the proliferation and mesenchymal differentiation of mononuclear cells. Our results are clinically relevant because it provide a new method for the acquisition of MSCs which can be used as a candidate for the wound repair.
\end{abstract}

Key words: Bone marrow mesenchymal stromal cells; Peripheral blood mesenchymal stromal cells;

Cell differentiation; Wound healing

\section{INTRODUCTION}

Increasing evidence has confirmed that bone marrow mesenchymal stromal cells (bmMSCs) can contribute to wound healing in vivo [1-5], and can differentiate into skin cells in vitro including keratinocytes [6], vascular endothelial cells [7], sweat gland cells [8], etc. Due to indirect connection between marrow stroma and remote tissues or organs, mesenchymal stem cells (MSCs) circulating in the pe- 
ripheral blood (peripheral blood-derived mesenchymal stem cells, pbMSCs) are hypothesized to be a source of tissue regeneration and repair. This indicates an ever-increasing recognition of the potential roles of pbMSCs in the regenerative medicine. Due to painful aspiration of bone marrow from patients, peripheral blood is considered as an alternative source of MSCs in clinical practice.

The attempts to demonstrate pbMSCs have been unrewarding, except for a report by Fernandez et al [9], who identified cells with the features of MSCs in the growth-factor-mobilized peripheral blood cells from breast-cancer patients. Several studies have conducted to isolate MSCs from the peripheral blood using culture conditions similar to those defined for bmMSCs [9-13], and their results support the existence of a small population of circulating MSCs. But the isolation of MSCs from the peripheral blood is clearly a challenge and these cells are subject to variation depending on the methods for isolation and sorting of mononuclear cells, and on culture conditions.

We isolated a subpopulation with fibroblast-like and stromal morphology from mononuclear cells following skin wound. These cells appeared different from the circulating fibrocytes of hematopoietic origin. We speculated these cells were pbMSCs. Considering the potential of MSCs in wound healing and that the amount of the isolated pbMSCs are not enough to meet the requirement for transplantation, it is imperative to develop new methods which can effectively stimulate cell propagation and differentiation.

Previously, bmMSCs were studied for their roles in the hemopoiesis, where they can promote the differentiation and proliferation of hemopoietic stem cells through providing signals and/or via the direct cell-cell interactions of their progeny and via the secretion of growth factors and chemokines [14-16]. Under the culture conditions, these adherent, spindle-shaped stromal cells are found to exhibit the potentials of multilineage mesenchymal differentiation including osteogenesis, chondrogenesis and lipogenesis [17]. We accordingly hypothesized that some growth factors and chemokines in the supernatant of bmMSCs probably provide a microenvironment for the mesenchymal differentiation of pbMSCs.

In the present study, the mononuclear cells and isolated pbMNCs following skin wound were co-cultured in the conditioned medium which was prepared from the supernatant of bmMSCs. The characteristics of pbMNCs following induction were determined and their protective role in the wound repair was investigated.

\section{MATERIALS AND METHODS}

Preparation of conditioned medium and skin wound and isolation of mononuclear cells

This study was approved by the Animal Ethics Committee of the Fourth Military Medical University. Bone marrow was aspirated from the tibia and femur of 2-week-old Sprague-Dawley (SD) rats, and added into $7 \mathrm{ml}$ of Percoll-Paque (1.085 g/ml; Sigma, USA) in a 15-ml tube (Corning, USA) followed by density gradient centrifugation at 2,100 rpm for $20 \mathrm{~min}$. The cells in the interface layer were collected into a new tube, and then washed twice in phosphate-buffered saline (PBS) followed by re-suspension in the minimal essential medium (a-MEM; GIBCO, USA) containing $10 \%$ fetal calf serum (FCS; GIBCO, USA), $0.2 \mathrm{mM}$ L-glutamine (Sigma, USA), $100 \mathrm{IU} / \mathrm{ml}$ penicillin and $100 \mu \mathrm{g} / \mathrm{ml}$ streptomycin (Sigma, USA). The nucleated cells were seeded in $75-\mathrm{cm}^{2}$ dishes at a density of $1 \times 10^{5}$ cells $/ \mathrm{cm}^{2}$ followed by incubation in a humidified atmosphere with $5 \% \mathrm{CO}_{2}$ at $37^{\circ} \mathrm{C}$. The medium was refreshed every 2 days and primary culture was conducted for 7-8 days. After 7 days of culture, the medium was collected by centrifugation at $800 \mathrm{rpm}$ for 5 min during the third passaging when the bMSC confluence was near $100 \%$. The supernatant was collected and stored at $-80^{\circ} \mathrm{C}$. This supernatant was named conditioned medium.

Sixty SD rats aged 8 weeks weighing 200 220 g were randomly divided into three groups: 1) Normal group, 2) Wound group and 3) Wound+conditioned medium group. Animals in the latter two groups were intraperitoneally anesthetized with $0.1 \%$ pentobarbital sodium and a single full-thickness round wound of skin (about $2 \mathrm{~cm}$ in diameter) was created in the dorsal area of each rat. Five days later, $5 \mathrm{ml}$ of blood were obtained from the femoral vein of each rat and mononuclear cells were isolated with the same procedures used in the isolation of bmMSCs.

\section{Conditioned medium induction}

Heparin anti-coagulated peripheral blood was obtained, added to tubes and mixed with PBS of equal volume. The cell suspension was added onto 7-ml Percoll-Paque (1.083 g/ml; GE Healthcare, UK) in a $15-\mathrm{ml}$ tube. Centrifugation was performed at 2,100 $\mathrm{rpm}$ for $20 \mathrm{~min}$. The cells in the interface layer were collected into another 15-ml tube, washed twice with PBS, and counted. After an additional wash with PBS, mononuclear cells isolated from rats in Normal group and Wound group were re-suspended in a-MEM containing 7\% FCS, $100 \mathrm{IU} / \mathrm{ml}$ penicillin, $100 \mu \mathrm{g} / \mathrm{ml}$ streptomycin and $0.2 \mathrm{mM}$ L-glutamine. These cells were seeded in 6-well plate at a density of $1 \times 10^{5}$ 
cells $/ \mathrm{cm}^{2}$ and incubated in a humidified atmosphere with $5 \% \mathrm{CO}_{2}$ at $37^{\circ} \mathrm{C}$. Mononuclear cells isolated from Wound+conditioned medium group were re-suspended in the medium containing $50 \%$ of a-MEM and $50 \%$ of conditioned medium, $7 \%$ FCS, 100 $\mathrm{IU} / \mathrm{ml}$ penicillin and $100 \mu \mathrm{g} / \mathrm{ml}$ streptomycin. The medium was refreshed every 3 days and the floating cells were removed.

\section{CFE assay}

The CFE was originally defined as the number of MSC colonies in per $1 \times 10^{5}$ marrow nucleated cells in the original bone marrow cell suspension [18]. Herein, the CFE was employed to quantitate the number of ipbMSC colonies in per million mononuclear cells in each group. The cells $\left(1 \times 10^{5}\right.$ cells) from bone marrow aspiration in each group were seeded in sextuplicates in 35-mm dishes and maintained for 14 days. The medium was refreshed every 3 days and colonies ( $>50$ cells) were counted under a dissecting microscope.

\section{RT- PCR}

Total RNA was extracted using the RNeasy extraction kit (Invitrogen, USA) and genomic DNA was removed by DNase I, according to the manufacturer's instructions. RNA was reversely transcribed in $20-\mu 1$ reaction mixture including $10 \mu \mathrm{l}$ of total RNA, $0.5 \mu \mathrm{g}$ of oligo-dT, $200 \mu \mathrm{M}$ each dNTP, $20 \mathrm{U}$ of RNasin and $200 \mathrm{U}$ of M-MLV Reverse Transcriptase (TaKaRa, Japan) and the buffers. The primers for $\beta$-actin, Collagen I and III were as follows:

$\beta$-actin forward: 5'-TGG AAT CCT GTG GCA TCC ATG AAA C-3'

reverse: 5'-TAA AAC GCA GCT CAG TAA CAG TCC G-3'

Collagen I forward: 5'-GGA GAG TAC TGG ATC GAC CCT AAC-3'

reverse: 5'-CTG ACC TGT CTC CAT GTT GCA-3'

Collagen III forward: 5'-GAA AAA ACC CTG CTC GGA ATT-3'

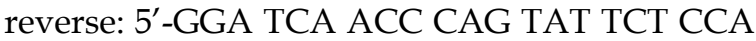

\section{CTCT-3'}

PCR was performed in $50-\mu l$ reaction mixture with $2 \mu \mathrm{l}$ of cDNA, $1.25 \mathrm{U}$ of Taq polymerase (TaKaRa, Japan), $200 \mu \mathrm{M}$ dNTPs, $0.4 \mu \mathrm{M}$ each primer, $1.5 \mathrm{mM} \mathrm{MgCl}_{2}$, the buffer and deionized water. The PCR conditions were as follows: for $\beta$-actin: pre-denaturation at $94^{\circ} \mathrm{C}$ for $2 \mathrm{~min}$ followed by $35 \mathrm{cy}-$ cles of denaturation at $94^{\circ} \mathrm{C}$ for $45 \mathrm{sec}$, annealing at $57^{\circ} \mathrm{C}$ for $45 \mathrm{sec}$ and extension at $72^{\circ} \mathrm{C}$ for $60 \mathrm{sec}$, and a final extension at $72^{\circ} \mathrm{C}$ for $10 \mathrm{~min}$ was also carried out. for Collagen I and III: 35 cycles of denaturation at $95^{\circ} \mathrm{C}$ for $30 \mathrm{sec}$, annealing at $90^{\circ} \mathrm{C}$ for $10 \mathrm{sec}$, and extension at $64^{\circ} \mathrm{C}$ for $30 \mathrm{sec}$. The products were separated by $1 \%$ agarose gel electrophoresis and stained with ethidium bromide. $\beta$-actin served as an internal reference.

\section{Phenotype and cell cycle analysis}

The ipbMSCs of passage 3 were grown on coverslips overnight for cell adherence. After washing with PBS, cells were fixed in formaldehyde for $10 \mathrm{~min}$ at room temperature and stained with mouse-anti-rat CD45 (1:100; AbD Serotec, UK), CD34 (1:100; Santa Cruz, USA), Collagen I (1:400; abcam, UK) or Vimentin (1:100; Millipore, USA) overnight at $4^{\circ} \mathrm{C}$. After washing with PBS 3 times, the slides were then reacted and visualized using DAB (EnVision ${ }^{\mathrm{TM}}$ Detection system, DAKO, Denmark). The mononuclear cells served as control positive for CD45 and CD34.

For flow cytometry analysis, following two washes, aliquots containing $10^{5}$ cells of mixture and ipbMSCs were incubated at $4^{\circ} \mathrm{C}$ for $1 \mathrm{~h}$ with $100 \mu \mathrm{l}$ of saturating concentration of mouse $\mathrm{mAb}$ against FITC-conjugated mouse mAb against CD45, CD90, PE-conjugated mouse $\mathrm{mAb}$ against $\mathrm{CD} 34$ and CD73, APC- conjugated mouse mAb against CD105 (all bought from eBioscience, USA) and isotype-matched control, independently. Following two washes, these cells were re-suspended in PBS. Quantitative fluorescence analysis was performed using an FACS Calibur cytometer and CellQuest software program (Becton Dickinson, USA). The cell number (at least 10,000 cells) versus fluorescence intensity was recorded in each sample.

When cell confluence reached $80 \%$, ipbMSCs in Wound+conditioned medium group and mononuclear cells in Wound group were trypsinized and the cell cycles were detected by flow cytometry (Beckman Coulter, USA).

\section{Osteogenic and adipogenic differentiation}

Osteogenic differentiation: The ipbMSCs of passage 3 were seeded in a 12-well plate at a density of $1 \times 10^{4}$ cells $/ \mathrm{cm}^{2}$. When cell confluence reached $80 \%$, the medium was replaced with osteogenic induction medium containing a-MEM, 7\% FCS, $0.1 \mu \mathrm{M}$ dexamethasone, $10 \mathrm{mM} \beta$-glycerolphosphate (Sigma, USA) and $50 \mathrm{mg} / \mathrm{L}$ ascorbate-2-phosphate. The medium was refreshed every 3 days. Three weeks later, mineralized nodules were stained with Alizarin Red S (Sigma, USA).

Adipogenic differentiation: The ipbMSCs of passage 3 was seeded in a 12-well plate at the same density. When cell confluence reached $80 \%$, the medium was replaced with adipogenic induction medium consisting of a-MEM, 7\% FCS, $0.25 \mu \mathrm{M}$ dexamethason, $100 \mu \mathrm{M}$ indomethacin (Sigma, USA), 0.5 
mM 3-isobutyl methylxanthine (Sigma, USA) and 10 $\mathrm{mg} / \mathrm{L}$ insulin. The medium was refreshed every 3 days. Two weeks later, neutral lipid vacuoles were stained with Oil-red O (Sigma, USA).

\section{Cell labeling and skin grafts preparation}

The ipbMSCs and bmMSCs were labeled with 10 $\mu \mathrm{M}$ fluorescent dye Hoechst33342 (Sigma, USA) in serum-free medium for $15 \mathrm{~min}$. Fluorescence was examined under inverted fluorescence microscope (Olympus IX51, Japan). After trypsinization, cells were mixed with type I collagen (Sigma, USA) and skin grafts were prepared as previously described in our lab [19].

\section{Preparation of skin wound and skin grafting}

Thirty six 10-week-old female nude mice were purchased from the Animal Center of the Fourth Military Medical University and divided into 3 groups (Graft+ipbMSCs+ Collagen I group; Graft+bmMSCs+ Collagen I group; Graft+Collagen I group). Animals were intraperitoneally anesthetized with $0.1 \%$ pentobarbital sodium and a full-thickness wound of skin $\left(1.5 \mathrm{~cm}^{2}\right)$ including the panniculus carnosus muscle was excised. Because the wound in the dorsal area was easily scratched by the animal and susceptible to spontaneous contraction due to the presence of surrounding loose tissue, the wound was created in the low part of the dorsal area. Skin grafts together with Collagen I and ipbMSCs $\left(1 \times 10^{6}\right.$ cells $)$ or bmMSCs $\left(1 \times 10^{6}\right.$ cells $)$ were transplanted to the wound independently. Then, the wound was covered with transparent semi-permeable membrane (Tegaderm, 3M, USA).

\section{Wound observation and fluorescence detection}

At 10 and 20 days after transplantation, the diameter of the wound was measured and the regenerated tissues including marginal normal skin $(2 \mathrm{~mm}$ in width) were collected. Half of the tissues were fixed in cool acetone for immunofluorescence detection and the remaining tissues fixed in $10 \%$ formalin for $\mathrm{H} \& \mathrm{E}$ staining.

\section{Histologic analysis}

Samples were cut into 5 - $\mu \mathrm{m}$ sections and antigen retrieval was performed in $10 \mathrm{mM}$ citrate buffer $(\mathrm{pH}$ 6.0 ) at $121^{\circ} \mathrm{C}$ for $15 \mathrm{~min}$. The sections were then treated with 3\% hydrogen peroxide to inactivate the endogenous peroxidase. After incubation with normal goat serum for $30 \mathrm{~min}$ to block the non-specific staining, the sections were treated with mouse-anti-rat collagen type I monoclonal antibody (1:800; Abcam, UK), or rabbit-anti-rat Ki67 polyclonal antibody (1:50; Abcam,
UK) for $1 \mathrm{~h}$ at $37^{\circ} \mathrm{C}$. The sections were then treated and visualized with DAB kit (EnVision ${ }^{\mathrm{TM}}$ Detection system, DAKO, Denmark), finally stained with hematoxylin and observed under light microscope. Samples from Collagen group served as negative control.

\section{Statistical analysis}

Data were expressed as mean \pm standard deviation (SD), and statistical analysis was performed with SPSS version 11.0 statistic software package. Comparisons were performed with $t$ test. A value of $\mathrm{P}<0.05$ was considered statistically significant.

\section{RESULTS}

CFE of fibroblast-like cells were increased after wound and conditioned medium induction

On the $3^{\text {rd }}$ day, adherent and spindle-shaped fibroblastic cells were noted in all groups, and the number of cells in Wound group was 3 5 times higher than that in the Normal group. In the Wound+conditioned medium group, the spindle-shaped cells were less noted and mostly replaced by cells with polygonal morphology. These cells aggregated forming clones. On the $6^{\text {th }}$ day, the cells propagated in Normal group and extensive cell network formed in Wound group. Clones in the Wound+conditioned medium group became enlarged and some of them contacted with each other (Fig. 1A). The morphology of ipbMSCs was stromal-like, especially at the $3^{\text {rd }}$ passage. They presented similar morphology in vitro to bmMSCs (Fig. 1B).

From the $3^{\text {rd }}$ day, colonies formed by fibroblastic cells were found in the mononuclear cells. The ipbMSCs colonies enlarged over time and the discrete colonies (1 5 $\mathrm{mm}$ in diameter) were observed on the $14^{\text {th }}$ day. The fibroblast colony-forming units (CFU-Fs) in Wound+conditioned medium group were about 3 times higher than that in the Wound group, and the CFU-Fs in the Wound+conditioned medium group and the Wound group were significantly higher than that in the Normal group $(\mathrm{P}<0.01)$ (Fig. 1C).

\section{Mesenchymal features of ipbMSCs}

The gene expressions of Collagen I and III were detected by RT-PCR and $\beta$-actin served as positive control (Fig. 2A). As shown in Figure 2A, ipbMSCs had expressions of Col-I and III. In addition, immunohistochemistry showed the ipbMSCs were negative and mononuclear cells positive for CD45 and CD34. ipbMSCs were also positive for collagen I and vimentin (Fig. 2B). 

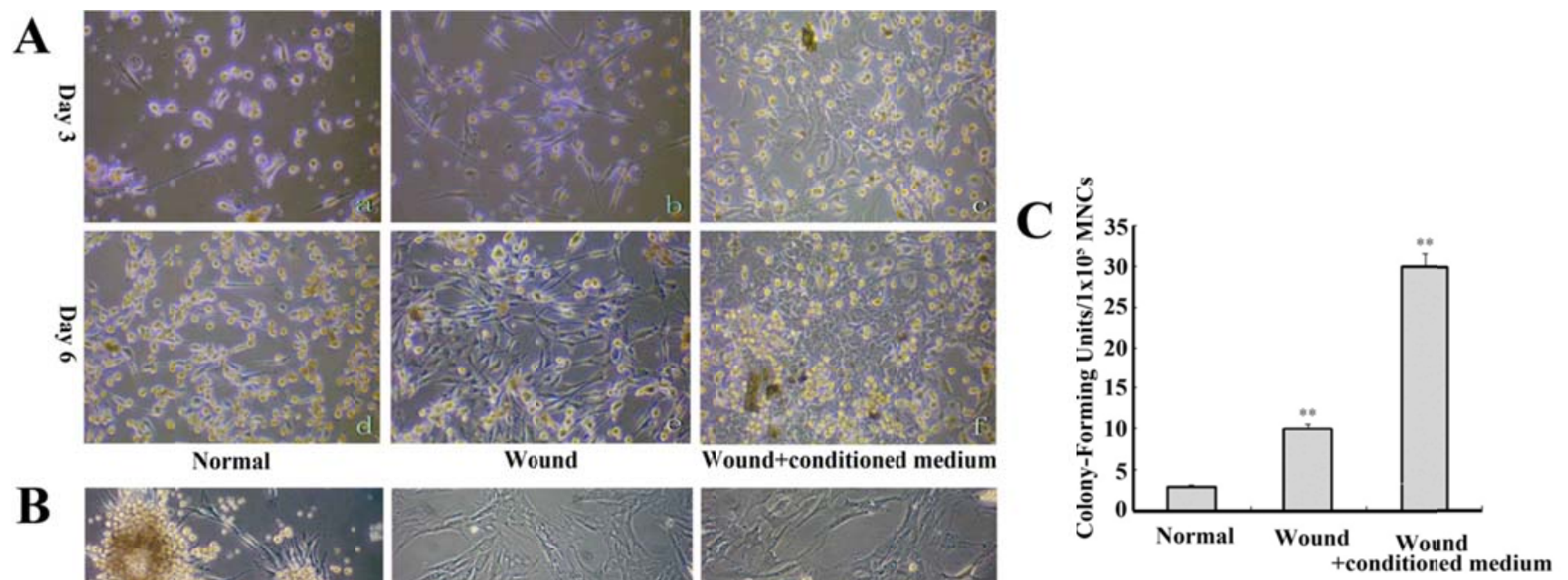

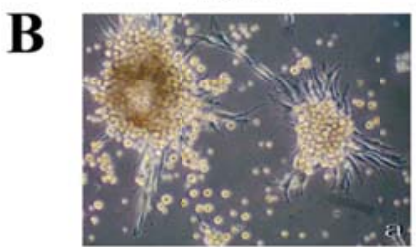

ipbMSCs P1

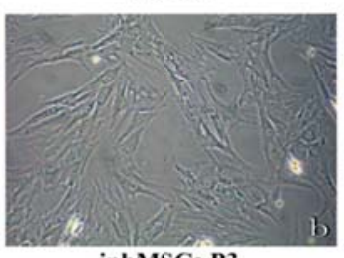

ipbMSCs P3

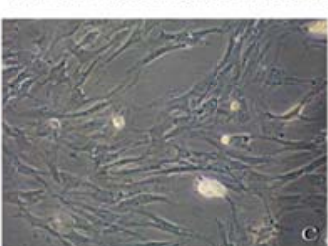

bmMSCs P3

Fig. I CFE of fibroblast-like cells was enhanced after wound pretreatment and conditioned medium induction. (A) Adherent, spindle-shaped fibroblastic cells were found in Normal group on the $3^{\text {rd }}$ day (a) and on the $6^{\text {th }}$ day (d). There were distinct morphologies. The number of fibroblastic cells was significantly increased and more extensive cell network formed in the Wound group (b) when compared with the Normal group (e). Spindle-shaped cells were less found, and most cells had polygonal morphology, aggregated and formed clones on the $3^{\text {rd }}$ day (c). These clones contacted with each other in Wound+conditioned medium group on the $6^{\text {th }}$ day ( $f$ ). (B) Fibroblastic cells formed colonies in the primary passage (a) and ipbMSCs (b) and bmMSCs (c) in the $3^{\text {rd }}$ passage had the stromal-like morphology. They were demonstrated to possess similar cell morphology in vitro. (C) The fibroblast colony-forming units (CFU-Fs) in the Wound+conditioned medium group were about 3 times higher than that in the Wound group, and significantly higher than that in the Normal group $(\mathrm{P}<0.01)$. (Magnification: 100x).

A

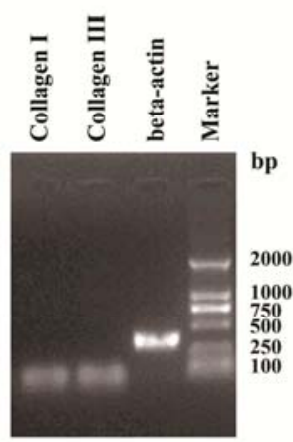

ipbMSCs

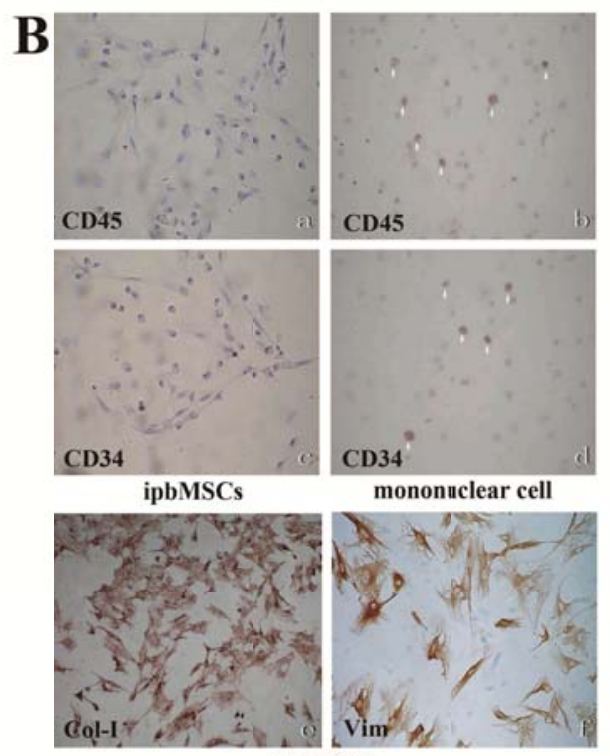

ipbMSCs
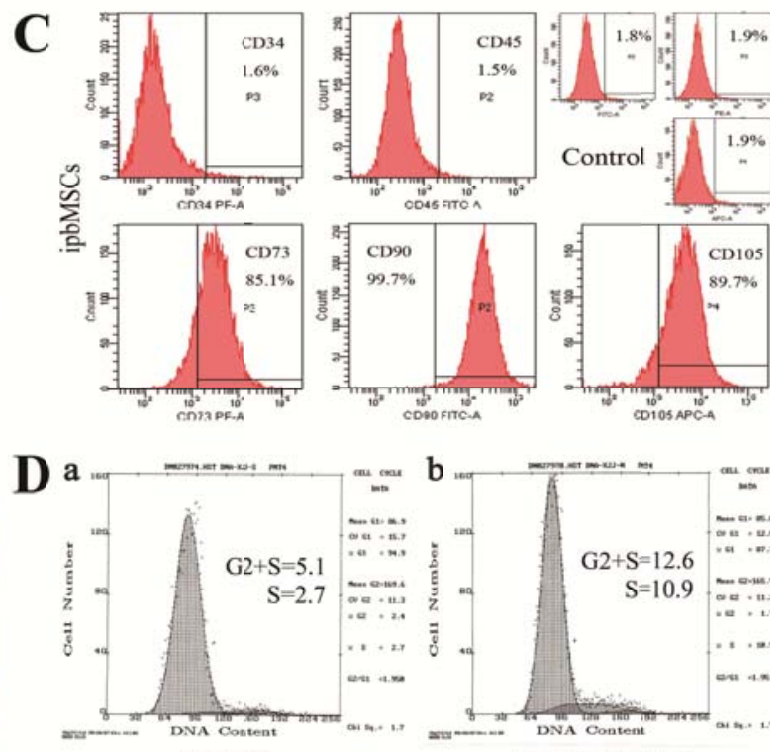

ipbMSCs

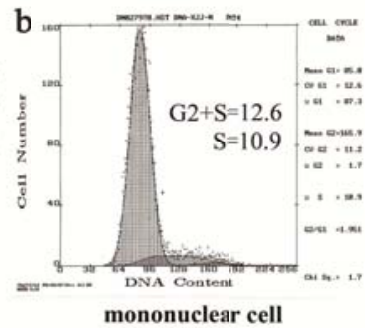

mononuclear cell

Fig.2 ipbMSCs expressed Collagen I and III and had mesenchymal features and higher proliferation potential than bmMSCs. (A) The mRNA expressions of Collagen I and III were detectable in ipbMSCs. (B) ipbMSCs were negative for CD45 (a) and CD34 (c) and mononuclear cells positive for these markers (b and d). ipbMSCs were positive for collagen I (e) and vimentin (f). (Magnification: 100x). (C) ipbMSCs had no expressions of markers for hematopoietic stem cells (CD34 [1.6\%] and CD45 
[1.5\%]), but highly expressed markers for MSCs (CD73 [85.1\%], CD90 [99.7\%] and CDI05 [89.7\%]). The proportion of FITC, PE and APC positive cells in isotype controlwas $1.8 \%, 1.9 \%$ and $1.9 \%$, respectively. (D) The proportion of ipbMSCs in $\mathrm{G} 2+\mathrm{S}$ phase and S phase was $5 . \mathrm{I}$ and 2.7, respectively which was significantly lower than those of mononuclear cells (I2.7 and I0.9, respectively).

ipbMSCs of passage 3 had almost no expressions of markers for hematopoietic stem cells (CD34 [1.6\%] and CD45 [1.5\%]), but highly expressed markers for MSCs (CD73 [85.1\%], CD90 [99.7\%] and CD105 [89.7\%]). The proportion of FITC, PE and APC positive cells in isotype control was $1.8 \%, 1.9 \%$ and $1.9 \%$, respectively. These results suggested ipbMSCs were MSCs derived. Cell cycle analysis showed the proportions of ipbMSCs in the G2+S phase and the $S$ phase were 5.1 and 2.7, respectively, both of which were significantly lower than those of mononuclear cells (12.7 and 10.9, respectively) (Fig. 2D). These findings suggested, under the conditioned medium induction, the proliferation of mononuclear cells was inhibited but their differentiation into mesenchymal lineages was enhanced.

\section{Multi-differentiation potential of ipbMSCs}

ipbMSCs exhibited osteogenic and adipogenic potentials when they were maintained in specific induction medium, which was demonstrated by the formation of calcium nodules and lipid droplets detected by staining of Alizarin Red S and Oil red-O, respectively (Fig. 3).

\section{Skin graft in combination with ipbMSCs and collagen I accelerates wound healing}

ipbMSCs and bmMSCs were labeled with Hoechst33342 and round skin grafts $(1.5-\mathrm{cm}$ in diameter) were prepared and preserved in culture medium (Fig. 4A). After solidification, the grafts were transplanted to the wound (Fig. 4B). On the $10^{\text {th }}$ day, the diameter of wound in both ipbMSCs group and bmMSCs group were about $5 \mathrm{~mm}$, and that in Collagen group was $7 \mathrm{~mm}(\mathrm{P}<0.05)$. There was no signifi- cant difference in the wound diameter between the ipbMSCs group and the bmMSCs group $(\mathrm{P}>0.05)$. On the $20^{\text {th }}$ day, scar was noted in the ipbMSCs group and the bmMSCs group, but a 2-mm wound was still unclosed in Collagen group $(\mathrm{P}<0.05)$ (Fig. 4B). These findings revealed ipbMSCs possessed similar potency in tissue repair to bmMSCs.

\section{Detection of fluorescence labeled cells and examination of skin structure after transplantation}

Blue fluorescence was detected in the ipbMSCs group and the bmMSCs group and the morphology of fluorescence was in consistent with the appearance in H\&E staining. No fluorescence was detected in the Collagen group (Fig. 5A).

Twenty days after transplantation, H\&E staining of the healed wound in the ipbMSCs and the bmMSCs group showed the number of epidermal cells was markedly higher than that in the Collagen group. The regenerated epidermal cells distributed unevenly in different layers, and the ridge became obvious in the epidermis. Even there were hair follicle-like structures in the regenerated dermis. In the healed wound in the Collagen group, however, the regenerated epidermal cells mainly distributed in the basal layer, and ridge or appendage-like structures were not found (Fig. 5B).

Positive staining for Ki67 and Collagen I was found in the regenerated epidermis and appendage-like structures in the wounds of both ipbMSCs and BMSCs groups. But the staining in the bmMSCs group was slightly stronger than that in the ipbMSCs group. However, the wound in the Collagen group was negative for Ki67 and Collagen I (Fig. 5C). 

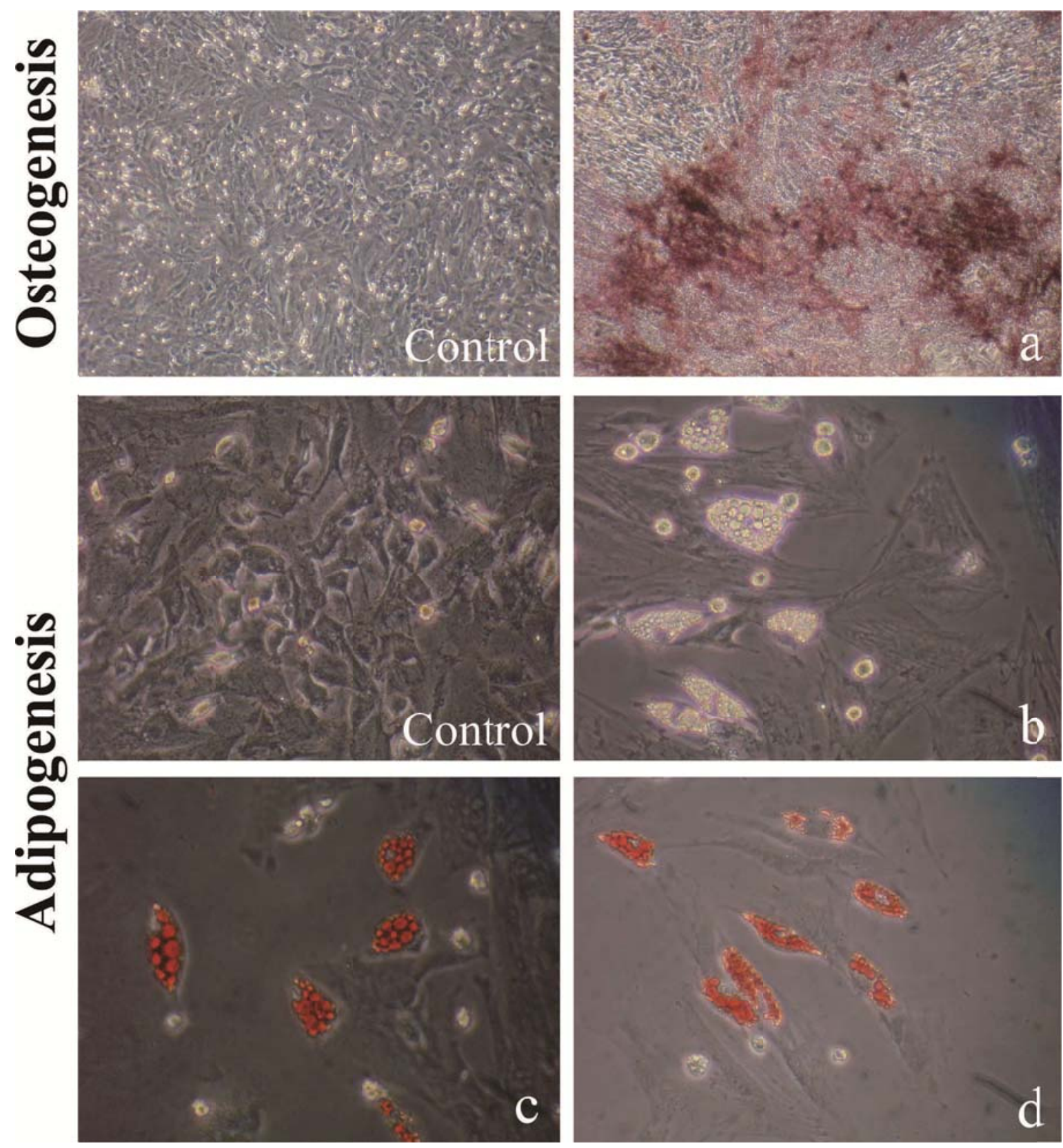

Fig.3 ipbMSCs have multipotent differentiation potentials into osteoblasts and adipocytes. After induction, ipbMSCs exhibited osteogenic and adipogenic potentials, which were demonstrated by staining of calcium nodules and lipid droplets (b), stained with Alizarin Red S (a) and Oil red-O (c, d), respectively. (Magnification: 200x). 


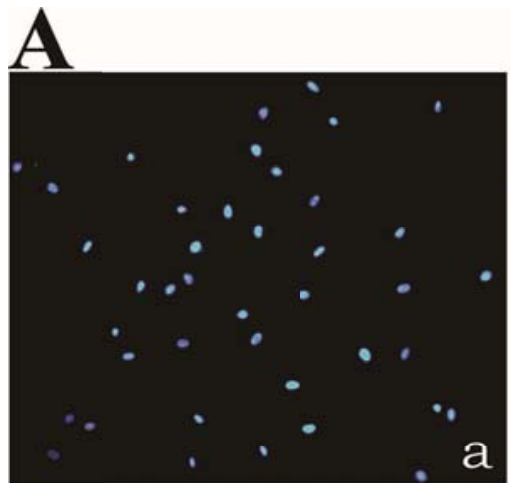

ipbMSCs
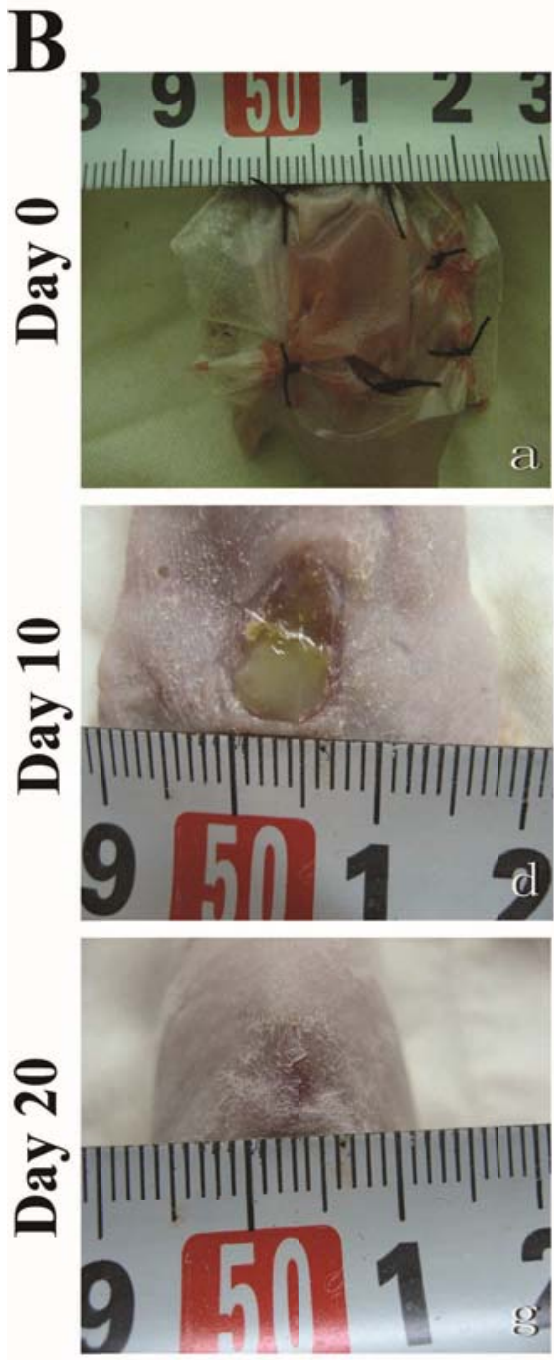

collagen I

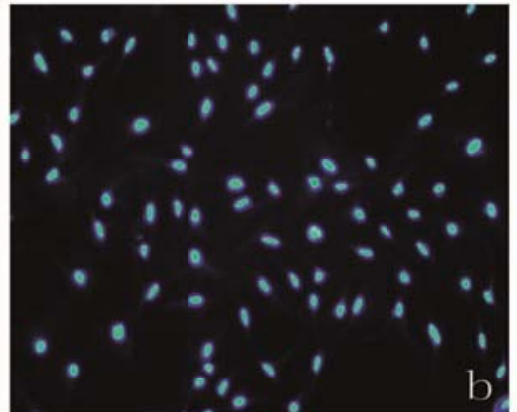

bmMSCs
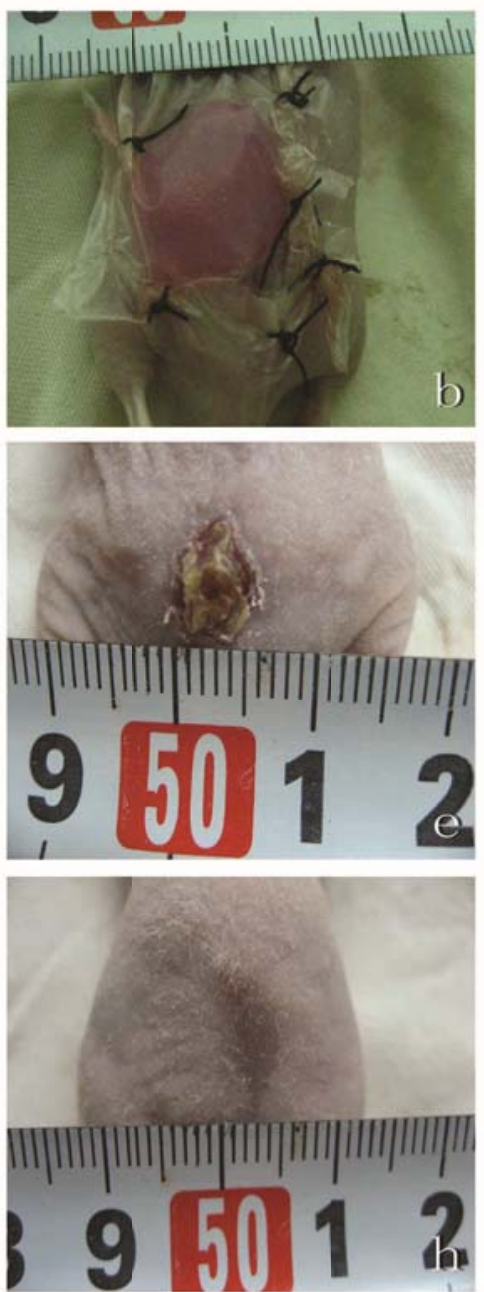

ipbMSCs

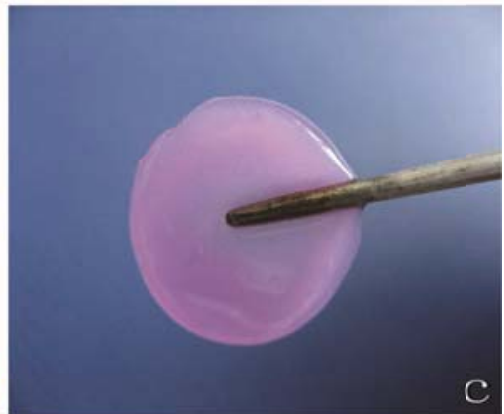

Skin graft
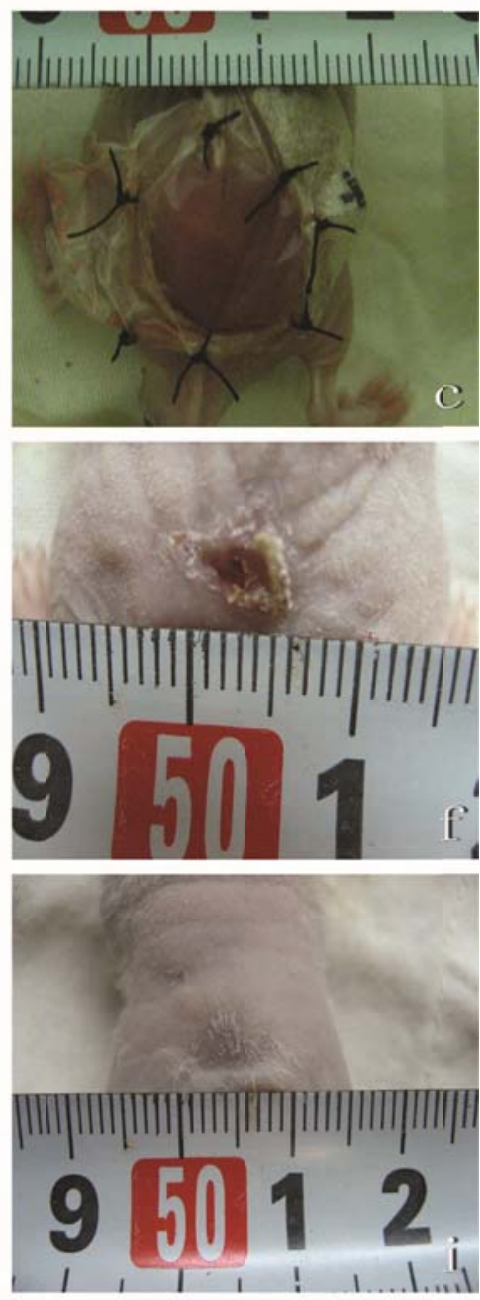

bmMSCs

Fig.4 Skin graft in combination with ipbMSCs and collagen I accelerated the wound healing. (A) ipbMSCs (a) and bmMSCs (b) were labeled by Hoechst 33342 and round skin grafts ( $1.5 \mathrm{~cm}$ in diameter) were prepared (c). (I00x). (B) Skin grafts were transplanted to the wound, which was then sutured and covered with transparent semi-permeable membrane (a: collagen I group; b: ipbMSCs group; c: bmMSCs group). On the $10^{\text {th }}$ day, the diameter of wound in both ipbMSCs group (e) and bmMSCs group (f) were about $5 \mathrm{~mm}$ and the wound were dry. The diameter of wound in the collagen group was about 7 $\mathrm{mm}$ and exudate was noted in the wound (d). On the $20^{\text {th }}$ day, scar was found in the ipbMSCs (h) group and the bmMSCs group (I) and a 2-mm wound was still unclosed in the collagen group (g). 
A

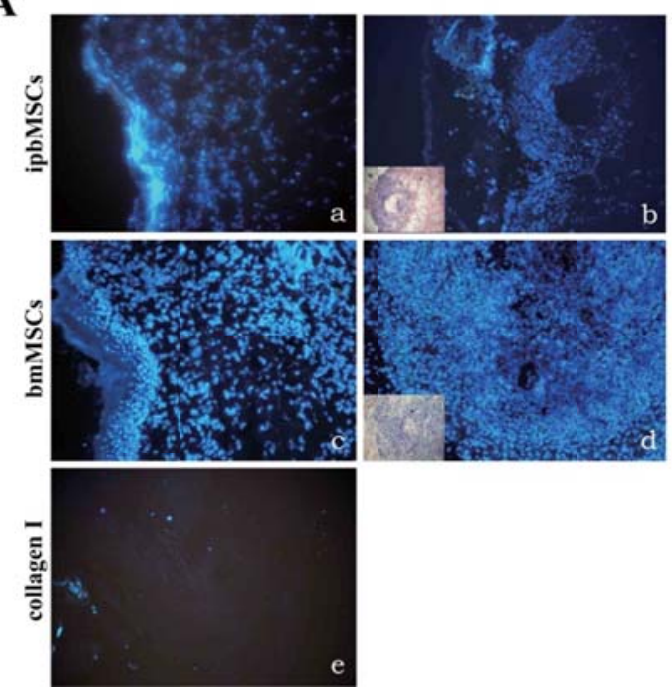

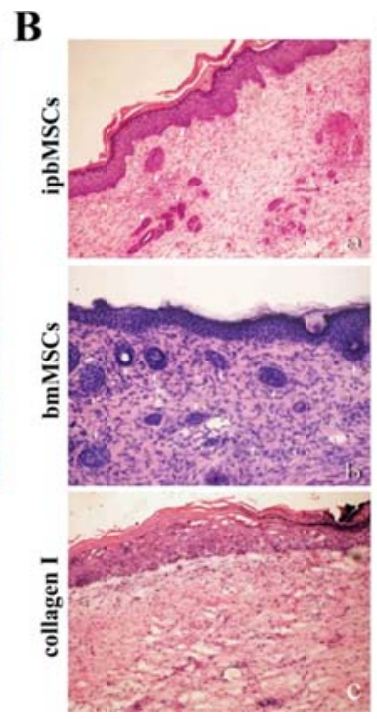
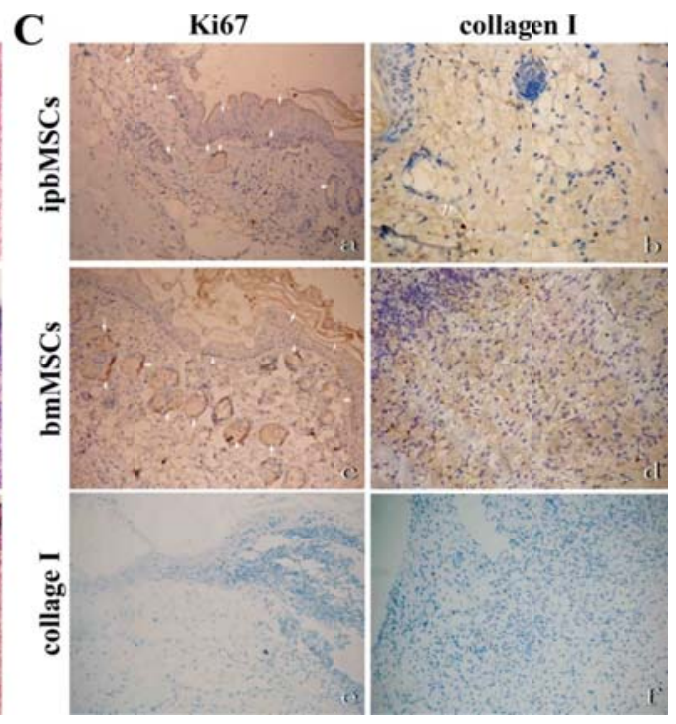

Fig.5 Detection of fluorescence labeled cells and observation of skin structure after transplantation. (A) Hoechst33342 labeled ipbMSCs (a) and bmMSCs (c) were detected under a fluorescence microscope and the morphology of fluorescence was in accordance with the appearance in the HE staining (b and d). No fluorescence was detected in the collagen group (e). (B) HE staining of the wound after treatment with skin grafts in combination with ipbMSCs (a) and bmMSCs (b) showed the number of epidermal cells was higher than that in collagen group (c). The regenerated epidermal cells unevenly distributed in different layers, and the ridge became obvious in the epidermis. Moreover, hair-follicle like structures were noted in the regenerated dermis ( $a$ and $b$ ). But in the collagen group, the regenerated epidermal cells mainly distributed in the basal layer, and ridge and appendage-like structure were not found (c). (C) After treatment with skin grafts together with ipbMSCs (a) and bmMSCs (c), the regenerated epidermis and appendage-like structures in the wound were positive for Ki67, and the expression of collagen I was slightly higher in the bmMSCs group (d) than that in the ipbMSCs group (b). In the collagen group, the wound was negative for Ki67 (e) and collagen I (f). (Magnification: 20x).

\section{DISCUSSION}

MSCs are multipotent cells capable of differentiating into various mesenchymal tissues, such as bone, cartilage, fat, tendon, muscle, etc. They can be found in both mesenchymal tissues and bone marrow. If bmMSCs are required for the repair and fibrosis of mesenchymal tissues, transit of these cells through the peripheral blood is to be expected. To date, at least two kinds of adherent cells have been isolated from the peripheral blood: one is circulating fibrocytes, which have the hematopoietic features (Collagen $\mathrm{I}+/ \mathrm{CD} 11 \mathrm{~b}+/ \mathrm{CD} 45+/ \mathrm{CD} 34+/ \mathrm{CD} 14+)$ and multi-differentiation potentials contributing to the wound healing [20-22]; the other is pbMSCs, which have the characteristics of mesenchymal lineages (CD45-/CD34-/CD29+/CD44+/CD90+/CD73+) and are similar to bmMSCs [23,24].

We speculate that pbMSCs might be an intermediate between the bone marrow and mesenchymal tissues in the requirement for repair, which is an important reason to use peripheral blood as a source of MSCs. The concept of a continuous replacement of connective tissue with marrow cells parallels the known continuous replacement of blood by bone marrow hematopoietic cells. Some investigations have shown that after systemic infusion, bmMSCs engraft within multiple tissues of mesenchymal origin in the adults [25, 26] suggesting that MSCs can serve as universal repair cells in the adult tissues as they undergo regeneration or remodeling $[27,28]$. Just like the hematopoietic stem cells were first found in the bone marrow and now can be harvested from the peripheral blood for clinical regeneration of bone marrow, MSCs were also first identified in the bone marrow and now can be harvested from a variety of tissues [29-32], affirmatively including the peripheral blood.

Another important reason for the selection of peripheral blood as a source is that pbMSCs probably retain the primitive characteristics of bmMSCs, which are different from the tissue-derived MSCs. It is unclear that why MSCs undergo multi-lineage differentiation in vitro, whereas they normally remain undifferentiated or produce daughter cells that differentiate only along the same lineage as the surrounding tissue in vivo. In the native environment, neighboring cells or matrix may send instructive signals that are absent in culture. Extracellular matrix can regulate the 
differentiation of cells [33], and may maintain the progenitor cells in a quiescent state until the tissue architecture is disrupted. Thus, the peripheral blood becomes a pure land for primitive MSCs circulating outside the bone marrow.

In the present study, more pbMSCs were isolated after wound pretreatment than under normal condition, which was consistent with previous studies $[34,35]$ that pbMSCs and endothelial progenitor cells were increased in the peripheral blood during wound repair. Badiavas et al. indicated that there was a significant number of bone marrow cells trafficing through both wounded and non-wounded skin, which implied that wounding could be a stimulus for the mobilization of bone marrow-derived mesenchymal stem cells to organs which facilitates the regeneration of damaged tissues [36]. In recent years, several studies suggest that bmMSCs, endothelial progenitor cells and fibrocytes may be involved in the tissue repair, contributing to differentiation into skin cells and/or release of regulatory cytokines [22, 37, 38]. Therefore, wounding may stimulate the engraftment of bone marrow cells to the wounded skins and induce these cells to incorporate and differentiate into non-hematopoietic skin cells.

Because the re-epithelialization and formation of granulation tissues are the major factors involving in the wound healing $[39,40]$, we speculate that MSCs play an important role in the healing process of mesenchyme, which was confirmed by the formation of appendage-like structure and epidermal ridge in the present study. This was also consistent with a recent study of $\mathrm{Wu}$ et al [41], who found that implanted CD34+ bone marrow cells did not express cytokeratin or incorporate into skin epidermis and its appendages in the wound. bmMSCs also have the angiogenic potential. They can differentiate into smooth muscle cells in vitro [42], and the bone marrow-derived cells seeded on a synthetic vascular graft can form smooth muscle and endothelial layers in vivo [43], which implies that the growth of MSCs in the injured vascular tissues may regenerate the normal vascular tissues.

Sufficient cell provision is one of the important factors determining the successful application of cell therapy. Insufficiency of MSCs circulating in the peripheral blood limits the wide application of these cells. In the present experiment, the isolation efficiency and CFE of the pbMSCs after conditioned medium incubation (Wound+ conditioned medium group) were much higher than that in the Wound group and the normal group. We speculate that the developmental microenvironment is critical for the growth and differentiation of pbMSCs. The cytokines secreted by the bmMSCs can induce the differentia- tion of mononuclear cells into the mesenchymal lineage and stimulate the mobilization of MSCs from the bone marrow into the peripheral blood. Some studies have confirmed that bmMSCs can secret a variety of cytokines including TGF- $\beta 1$ [44], G-CSF, GM-CSF $[45,46]$ and VEGF [47]. bmMSCs in vitro have been found to secret VEGF, basic fibroblast growth factor (bFGF), placental growth factor (PIGF), and monocyte chemoattractant protein-1 (MCP-1) [48]. Although these factors play important roles in the cell growth and differentiation, the maintenance of the primitive characteristics of MSCs as in the bone marrow possibly cannot be done by any one of them and requires interaction with each other.

The ipbMSCs have the characteristics of MSCs, and are negative for CD34 and CD45, but positive for Vimentin and Collagen I. Results from skin grafting showed the skin graft in combination with ipbMSCs and Collagen I effectively promoted the wound healing and showed similar potency in the promotion of wound healing to bmMSCs. These findings suggest ipbMSCs can be used as a candidate for cell therapy and have the potential to substitute bmMSCs as seed cells in the tissue engineering of skin. Because bmMSCs have the potential in the cutaneous reconstitution, human bmMSCs populated porcine skin substitute has been applied in the treatment of full-thickness wound of skin in nude rats achieving favorable outcome [49]. It has been confirmed that bmMSCs can contribute to the wound healing through their differentiation, deposition of collagen secreted by these cells and their angiogenesis [41,50]. Direct injection of bmMSCs into the injured site shows improved repair due to the differentiation of bmMSCs and/or the release of paracrine factors. The ipbMSCs may play similar roles in this process.

As a source of seed cells for tissue repair, the ipbMSCs have advantage of promptness and efficiency in cell propagation under control in vitro. Furthermore, the acquisition of these cells is less painful and they are more accessible when compared with bmMSCs. Nevertheless, there are still problems remaining to resolve: 1) The conditioned medium of bmMSCs is a mixture of growth factors and chemokines, and it is unclear which factor plays the most or more important role or which factor cooperates well to support the cell growth and differentiation; 2) The conditioned medium of bmMSCs is critical for the efficient and stable induction of MSCs; 3) Assurance of normal bmMSCs is crucial for the safe application of ipbMSCs.

\section{ACKNOWLEDGMENTS}

The study was supported by the National High 
Technology Research and Development Program of China (863 Project) (Grant No: 2006AA02A119) and the Fundamental Research Funds for the Central Universities.

\section{COMPETING INTERESTS}

The authors declare no competing financial interests.

\section{REFERENCES}

1. Ouyang HW, Goh JC, Lee EH. Use of bone marrow stromal cells for tendon graft-to-bone healing: histological and im-munohistochemical studies in a rabbit model. Am J Sports Med 2004;32: 321.

2. Abdel-Hamid M, Hussein MR, Ahmad AF, et al. Enhancement of the repair of meniscal wounds in the red-white zone (middle third) by the injection of bone marrow cells in canine animal model. Int J Exp Pathol 2005;86: 117.

3. Mankani MH, Kuznetsov SA, Shannon B, et al. Canine cranial reconstruction using autologous bone marrow stromal cells. Am J Pathol 2006;168: 542.

4. McFarlin K, Gao X, Liu YB, et al. Bone marrow-derived mes-enchymal stromal cells accelerate wound healing in the rat. Wound Repair Regen 2006;14: 471.

5. Kwon DS, Gao X, Liu YB, et al. Treatment with bone mar-row-derived stromal cells accelerates wound healing in diabetic rats. Int Wound J 2008;5: 453.

6. Han C, Wang S, Lai P, et al. Human bone marrow-derived mesenchymal stem cells differentiate into epidermal-like cells in vitro. Differentiation 2007;75: 292.

7. Hegner B, Weber M, Dragun D, et al. Differential regulation of smooth muscle markers in human bone marrow-derived mes-enchymal stem cells. J Hypertens 2005;23: 1191.

8. Li $\mathrm{H}, \mathrm{Fu} \mathrm{X}$, Ouyang $\mathrm{Y}$, et al. Adult bone-marrow-derived mes-enchymal stem cells contribute to wound healing of skin ap-pendages. Cell Tissue Res 2006;326: 725.

9. Fernández M, Simon V, Herrera G, et al. Detection of stromal cells in peripheral blood progenitor cell collections from breast cancer patients. Bone Marrow Transplant 1997;20: 265

10. Tondreau T, Meuleman N, Delforge A, et al. Mesenchymal stem cells derived from CD133-positive cells in mobilized peripheral blood and cord blood: proliferation, Oct4 expression, and plas-ticity. Stem Cells 2005;23: 1105

11. Wexler SA, Donaldson C, Denning-Kendall P, et al. Adult bone marrow is a rich source of human mesenchymal 'stem' cells but umbilical cord and mobilized adult blood are not. Br J Haematol 2003;121: 368

12. Zvaifler NJ, Marinova-Mutafchieva L, Adams G, et al. Mesen-chymal precursor cells in the blood of normal individuals. Arthritis Res 2000;2: 477

13. Kuznetsov SA, Mankani MH, Gronthos S, et al. Circulating skeletal stem cells. J Cell Biol 2001;153: 1133

14. Hofer M, Vacek A, Pospísil M, et al. Adenosine potentiates stimulatory effects on granulocyte-macrophage hematopoietic progenitor cells in vitro of IL-3 and SCF, but not those of G-CSF, GM-CSF and IL-11. Physiol Res 2005;55: 591

15. Feugier P, Li N, Jo DY, et al. Osteopetrotic mouse stroma with thrombopoietin, c-kit ligand, and flk-2 ligand supports long-term mobilized CD34+ hematopoiesis in vitro. Stem Cells Dev 2005;14: 505

16. Nolta JA, Thiemann FT, Arakawa-Hoyt J, et al. The AFT024 stromal cell line supports long-term ex vivo maintenance of engrafting multipotent human hematopoietic progenitors. Leukemia 2002;16: 352
17. Sadan O, Melamed E, Offen D. Bone-marrow-derived mesen-chymal stem cell therapy for neurodegenerative diseases. Expert Opin Biol Ther 2009;9: 1487

18. Mezey E, Mayer B, Németh K. Unexpected roles for bone marrow stromal cells (or MSCs): a real promise for cellular, but not replacement, therapy. Oral Dis 2010;16: 129

19. Liu Y, Suwa F, Wang X, et al. Reconstruction of a tis-sue-engineered skin containing melanocytes. Cell Biol Int 2007;31: 985

20. Metz CN. Fibrocytes: a unique cell population implicated in wound healing. Cell Mol Life Sci 2003;60: 1342

21. Abe R, Donnelly SC, Peng T, et al. Peripheral blood fibrocytes: differentiation pathway and migration to wound sites. J Im-munol 2001; 166: 7556

22. Mori L, Bellini A, Stacey MA, et al. Fibrocytes contribute to the myofibroblast population in wounded skin and originate from the bone marrow. Exp Cell Res 2005;304: 81

23. Wan $\mathrm{C}, \mathrm{He} \mathrm{Q}, \mathrm{Li}$ G. Allogenic peripheral blood derived mesen-chymal stem cells (MSCs) enhance bone regeneration in rabbit ulna critical-sized bone defect model. J Orthop Res 2006;24: 610

24. Ukai R, Honmou O, Harada K, et al. Mesenchymal stem cells derived from peripheral blood protects against ischemia. J neurotrauma 2007; 24: 508

25. Park J, Gelse K, Frank S, et al. Transgene-activated mesenchymal cells for articular cartilage repair: a comparison of primary bone marrow-, perichondrium/periosteum- and fat-derived cells. J Gene Med 2006;8: 112

26. Herzog EL, Chai L, Krause DS. Plasticity of marrow-derived stem cells. Blood 2003;102: 3483

27. Mödder UI, Khosla S. Skeletal stem/osteoprogenitor cells: current concepts, alternate hypotheses, and relationship to the bone remodeling compartment. J Cell Biochem 2008;103: 393

28. Hirschi KK, Goodell MA. Hematopoietic, vascular and cardiac fates of bone marrow-derived stem cells. Gene Ther 2002;9: 648

29. Zuk PA, Zhu M, Mizuno $H_{\text {, }}$ et al. . Multilineage cells from hu-man adipose tissue: implications for cell-based therapies. Tissue Eng 2001;7: 211

30. Mizuno H, Zuk PA, Zhu M, et al. Myogenic differentiation by human processed lipoaspirate cells. Plast Reconstr Surg 2002;109: 199

31. Campagnoli C, Roberts IA, Kumar S, et al. Identification of mesenchymal stem/progenitor cells in human first-trimester fetal blood, liver, and bone marrow. Blood 2001; $98: 2396$

32. Erices A, Conget $P$, Minguell JJ. Mesenchymal progenitor cells in human umbilical cord blood. Br J Haematol 2000;109: 235

33. Katz E, Streuli $\mathrm{CH}$. The extracellular matrix as an adhesion checkpoint for mammary epithelial function. Int J Biochem Cell Biol 2007;39: 715

34. Roufosse CA, Direkze NC, Otto WR, et al. Circulating mesen-chymal stem cells. Int J Biochem Cell Biol 2004;36: 585

35. Mansilla E, Marín GH, Drago H, et al. Bloodstream Cells Phe-notypically Identical to Human Mesenchymal Bone Marrow Stem Cells Circulate in Large Amounts Under the Influence of Acute Large Skin Damage: New Evidence for Their Use in Re-generative Medicine. Transplant Proc 2006;38: 967

36. Badiavas EV, Abedi M, Butmarc J, et al. Participation of bone marrow derived cells in cutaneous wound healing. J Cell Physiol 2003;196: 245

37. Sasaki M, Abe R, Fujita Y, et al. Mesenchymal stem cells are recruited into wounded skin and contribute to wound repair by transdifferentiation into multiple skin cell type. J Immunol 2008;180: 2581

38. Suh W, Kim KL, Kim JM, et al. Transplantation of endothelial progenitor cells accelerates dermal wound healing with in-creased recruitment of monocytes/macrophages and neovas-cularization. Stem Cells 2005;23: 1571 
39. Dorsett-Martin WA. Rat models of skin wound healing: a review. Wound Repair Regen 2004;12: 591

40. Greenhalgh DG, Warden GD. Wound care models. In: Souba WW, Wilmore DW, editors. Surgical research. London: Academic Press 2001:379-391.

41. Wu Y, Chen L, Scott PG, et al. Mesenchymal stem cells enhance wound healing through differentiation and angiogenesis. Stem Cells 2007;25: 2648

42. Kashiwakura Y, Katoh Y, Tamayose K, et al. Isolation of bone marrow stromal cell-derived smooth muscle cells by a human SM22alpha promoter: in vitro differentiation of putative smooth muscle progenitor cells of bone marrow. Circulation 2003;107: 2078

43. Matsumura G, Miyagawa-Tomita S, Shin'oka T, et al. First evi-dence that bone marrow cells contribute to the construction of tissue-engineered vascular autografts in vivo. Circulation 2003;108: 1729

44. Liu Y, Dulchavsky DS, Gao X, et al. Wound repair by bone marrow stromal cells through growth factor production. J Surg Res 2006;136: 336

45. de Wynter E, Allen T, Coutinho L, et al. Localisation of granu-locyte macrophage colony-stimulating factor in human long-term bone marrow cultures. Biological and immunocyto-chemical characterisation. J Cell Sci 1993;106: 761

46. Besse A, Trimoreau F, Praloran V, et al. Effect of cytokines and growth factors on the macrophage colony-stimulating factor secretion by human bone marrow stromal cells. Cytokine 2000;12: 522

47. Majumdar MK, Thiede MA, Haynesworth SE, et al. Human marrow-derived mesenchymal stem cells (MSCs) express hem-atopoietic cytokines and support long-term hematopoiesis when differentiated toward stroma and osteogenic lineages. J Hematother Stem Cell 2000; 9: 841

48. Kinnaird T, Stabile E, Burnett MS, et al. Local delivery of mar-row-derived stromal cells augments collateral perfusion through paracrine mechanisms. Circulation 2004;109: 1543

49. Fu X, Li H. Mesenchymal stem cells and skin wound repair and regeneration: possibilities and questions. Cell Tissue Res 2009;335: 317

50. Fathke C, Wilson L, Hutter J, et al. Contribution of bone mar-row-derived cells to skin: collagen deposition and wound repair. Stem Cells 2004;22: 812 